\title{
Da soberba à humildade: - Auto da sibila Cassandra, de Gil Vicente
}

\author{
From proudness to humbleness: Gil Vicente's Auto da sibila Cassandra
}

\author{
LUÍS ANDRÉ NEPOMUCENO \\ Centro Universitário de Patos de Minas
}

ar

\begin{abstract}
Resumo: Gil Vicente escreveu boa parte de seu teatro devocional a partir do "ciclo da natividade", disseminado pelas moralidades e milagres típicos da dramaturgia medieval. Compondo uma face desse ciclo, o Auto da sibila Cassandra (ca. 1509-1513), a exemplo dos demais textos vicentinos desse período, termina com a cena do presépio como modelo máximo de humildade, antítese do "mundo às avessas" representado no primeiro quadro da peça. O presente artigo analisa os personagens centrais do auto, Cassandra e Salomão, como identidades de culturas distintas (a tradição clássica e o mundo do Antigo Testamento), ambas imbuídas da soberba que caracteriza o pecado de Lúcifer, porém levadas ao reconhecimento do erro, bem como à piedade e à adoração que movem o ciclo da natividade do teatro medieval. Uma breve análise histórica sobre o pecado do orgulho, fundamentada sobretudo em Agostinho e Tomás de Aquino, sustenta o entendimento da ação composta por Gil Vicente.
\end{abstract}

Palavras-chave: teatro português; auto de moralidade; pecados capitais; Escolástica.

\begin{abstract}
Gil Vicente wrote a good part of his devotional theater considering the "cycle of nativity", disseminated by the miracle and morality plays typical of medieval drama. Composing a part of this cycle, the Auto da sibila Cassandra (ca. 1509-1513), together with other vicentine texts of this period, ends with the nativity scene as the greatest model of humility, antithesis of the topsy-turvy world represented in the first frame of the play. The present paper analyzes the central characters of the auto, Cassandra and Salomon, as identities of different cultures (the classical tradition and the Old Testament world), both imbued with the pride that characterizes Lucifer's sin, however taken to the acknowledgment of their fault, as well as to the piety and adoration that move the cycle of nativity of medieval drama. A brief historical analysis about the sin of pride, founded especially on Augustine and Thomas Aquinas, sustains the understanding of this action composed by Gil Vicente.
\end{abstract}

Keywords: Portuguese theater; morality plays; capital sins; Scholastics.

Em linhas gerais, é possível dizer que o Auto da sibila Cassandra, de Gil Vicente, é peça natalina que se utiliza de personagens extraídos de culturas tão díspares quanto inconciliáveis, mantidos à roda do presépio e inclinados à adoração do menino recém-nascido, como sói acontecer na imensa parte das composições da fase pastoril do autor. Reis Magos, Pastoril Castelhano, Fé, Quatro Tempos e a própria Sibila Cassandra são textos de uma mesma fase, escritos pelo menos até 1513, em que personagens, em geral pastores rústicos ou aldeões, interagem em situações diversas, apenas como pretexto para a exposição da cena da natividade no fecho de cada peça. Era a fase inicial de Gil Vicente, tomada ainda pelas sugestões e pela autoridade das éclogas pastoris de Juan del Encina e Lucas Fernández, dramaturgos da vizinha
Espanha que favoreceram a consolidação do estilo pastoril e doutrinário do teatro tardo-medieval.

Quanto às saídas doutrinárias centradas no presépio, lembre-se a observação de Dalila Pereira da Costa (1989, p.67), quando ela diz que "em todas as grandes obras do teatro religioso de Gil Vicente, o fecho será a vinda de Cristo", seja o Cristo da eucaristia, o do presépio, o da ressurreição ou o da libertação dos bem-aventurados. Quanto a isso, lembre-se que conforme o calendário do ano religioso, o teatro medieval parte-se em dois grandes ciclos: a Natividade e a Paixão, como dois elementos que se completam e se justificam, ou como duas faces do grande mistério da encarnação. No ciclo da natividade (que inclui as profecias, a natividade propriamente dita e a epifania), estampa-se o primeiro teatro devocional de 
Gil Vicente, incluindo-se aí a Sibila Cassandra. A respeito desse calendário litúrgico da dramaturgia medieval, acrescenta Saraiva (1970, p. 105) que "a Virgem é uma das metades do mistério".

Escrito provavelmente entre 1509 e $1513^{1}$, o Auto da Sibila Cassandra, a julgar pela simplicidade pastorícia das demais composições natalinas da primeira fase, mantémse como peça diferenciada, de trama e personagens mais complexos, de referencial mais amplo, exibindo um universo literário de maior alcance por parte do autor. $\mathrm{O}$ importante vicentista Paul Teyssier (1982, p. 43) mostra que, com Sibila Cassandra, há "novo progresso" que se registra no teatro do mestre português, em especial na construção da personagem que leva o nome da peça. A Cassandra de Gil Vicente, profetisa do acervo clássico, provavelmente extraída da Cronica Troiana que circulou pela Europa na Idade Média, prediz que o filho de Deus nascerá de uma virgem, e por presunção, acredita que ela será a eleita. Por isso, e para manter-se casta, recusa obstinadamente o pedido de casamento de Salomão. Sim, ele mesmo: o patriarca bíblico, autor do Cântico dos Cânticos. Mesmo sob a solicitação de suas "tias" que entram em cena (Erutea, Peresica e Cimeria, outras sibilas do acervo clássico) e dos "tios" de Salomão que chegam depois (os patriarcas e profetas Abraão, Moisés e Isaías), Cassandra mantém-se turrona e inflexível, numa obstinação que beira a comicidade, não fossem os argumentos graves e sóbrios sobre as dificuldades do matrimônio para as mulheres daquele tempo. Nossa profetiza só irá reconhecer o seu orgulho, quando a cena da natividade se abrir aos olhos do espectador, revelando a virgem verdadeira e os mistérios do nascimento de Cristo: "no te oso pedir nada/ porque nunca di passada/ concertada/ ni debiera ser nacida" (Cassandra, 734-737), ela diz à Virgem, na última de suas alocuções na peça ${ }^{2}$.

Assim, é possível entrever no auto pelo menos duas metades: na primeira parte, expõem-se os vícios e a perdição da alma orgulhosa de Cassandra, e numa segunda parte, a encenação do presépio, motivação recorrente no teatro devocional vicentino, como já se disse. Révah, que se debruçou sobre o texto, também dividiu a peça em duas partes: uma primeira, centrada na recusa de Cassandra e no seu discurso anticonjugal; e uma segunda, mantida sob a égide da revelação, das profecias e da própria natividade. A reviravolta das partes estaria em pelo menos duas declarações presunçosas de Cassandra a respeito de si mesma, contidas nos versos 427-432 e 506-511 (RÉVAH, 1959, p. 169-170).

Durante certo tempo, leitores vicentinos julgaram o Auto da sibila Cassandra como peça desconexa, abarrotada de elementos díspares, senão contraditórios e inconciliáveis na proposta inicial de encenação natalina: sibilas pagãs convivem com patriarcas bíblicos; personagens de tempos históricos incoadunáveis igualmente se relacionam; Cassandra menciona não querer ser monja, numa afirmativa anacrônica antes do nascimento de Cristo; a temática do casamento parece desajustada aos propósitos do fecho natalino, o tema da guerra dos cavaleiros na canção final não tem relação com o restante da peça, entre outros "problemas". Thomas Hart Jr., em meados do século passado, foi perspicaz quando apresentou a coerência e a unidade da matéria simbólica, em que cada item do auto funciona como elemento formal e tematicamente conciliável, a partir do conceito de alegoria medieval: "The simplest definition of allegory current in the Middle Ages is 'saying one thing to mean another', Isidore of Seville's 'alliud enim sonat, et aliud intelligitur" (HART Jr., 1958, p. 35). Se a alegoria medieval propõe dizer uma coisa para significar outra, as peças aparentemente díspares da composição de Gil Vicente mostram-se eficazes para chegar ao desfecho da encenação natalina, a se considerar, por exemplo, as seguintes questões: personagens pagãos e bíblicos unem-se em favor de uma profecia única do nascimento do Menino; a recusa de Cassandra revela-se igualmente a recusa do casamento com "a gente de Cristo" (representada simbolicamente por Salomão), e o orgulho da sibila é a antítese da humildade de Maria.

Frente a essas questões, muito crítico tem visto na obra a notória relação antitética entre orgulho e humildade, estampados respectivamente nas figuras de Cassandra e Maria: "orgulho e humildade podem ser considerados um par antitético a dinamizar uma peça que se movimenta continuamente num jogo de simetrias e oposições, para terminar no quadro vivo da adoração ao presépio" (CARNEIRO e LEVIN, in: VICENTE, 2007, p. 23). Trata-se do velho jogo de contrários que Gil Vicente tanto levou ao palco, especialmente na primeira fase de seu teatro devocional, escrito e representado sob o impacto dos milagres e das moralidades que percorriam a Europa naquele fim de Idade Média ${ }^{3}$ : no Auto Pastoril Castelhano, o pastor Brás é fútil e prazenteiro, enquanto Gil é contemplativo e despojado; em Reis Magos, os pastores são rústicos e vãos, enquanto o cavaleiro estampa a grandeza de ser nobre; em Mofina Mendes, a disparatada personagem do título é a antítese da Virgem Maria; e aqui na Sibila Cassandra, também a personagem

\footnotetext{
Saraiva (2000, p. 27) mantém a data tradicional de 1509, mas Braacamp Freire (1944, p. 155) e Teyssier (1982, p. 43) preferem o Natal de 1513.

2 As citações de Gil Vicente foram extraídas da edição As obras de Gil Vicente. Dir. José Camões. Lisboa: Imprensa Nacional - Casa da Moeda, 2002 (5v.). Os números posteriores ao título dos autos referem-se aos números dos versos.

3 Keates (1988, p. 51) acredita que a influência das moralidades francesas "não pode ter sido directa", na medida em que "não é possível, por outro lado, atribuir nem uma frase (nem sequer uma direção cénica) a qualquer fonte francesa como absoluta confiança". Assim, as influências do teatro medieval francês só poderão ter vindo por intermédio dos salmantinos (Encina e Fernández) que Vicente conheceu tão bem.
} 
que dá título ao auto é presunçosa e soberba, igualmente a antítese da Virgem. Em outros termos, Gil Vicente parece ter engendrado a primeira fase de seu teatro religioso por meio da exposição de contrários ou de condutas opostas, num jogo de vícios e virtudes, pecados e beneficências, com a inserção de tipos representativos de cada procedimento. Portanto, é justo pensar que na Sibila Cassandra o dramaturgo põe em cena a dualidade orgulho e humildade, conforme se vê nas figuras de Cassandra e Maria, como a evidenciar ao espectador a matéria doutrinária do pecado e da virtude que lhe servem de reflexão e apoio moral.

José Augusto Bernardes (2008, p. 52-53) notou que os autos dessa primeira fase do teatro religioso vicentino veem-se "assinalados, numa primeira parte, pela representação de vários tipos de desconcerto e, numa fase final, pela evocação do Presépio, servindo de resgate e de horizonte prospetivo". Quanto aos "desconcertos", ou vícios, será preciso considerar o conceito de mundus inversus (ou "mundo ao contrário"), proposto por João Nuno Alçada (2003, p.46-47) para designar uma visão específica de Gil Vicente e de seu tempo histórico a respeito de uma espécie de sensação de fim de mundo, gravada na inversão de valores morais e no apagamento da fé e dos costumes naqueles primórdios de um século de crises religiosas. É o que se lê, por exemplo, no Sermão (ou Pregação, conforme se lê na Compilação de 1562) escrito pelo dramaturgo em 1506, e dedicado a D. Leonor, sua rainha protetora. Desde esse tempo, Gil Vicente vinha denunciando seu olhar escatológico sobre o receio do fim dos tempos: "veo que el mundo está en conclusión" (Pregação, p. 176). Já no Sermão, o autor mostra-se o exegeta de um tempo em crise, denunciando como "sinais do fim dos tempos" aqueles vícios que ele posteriormente haveria de retratar nas suas farsas: a perda do gosto pela justiça, o império da falsidade, a falta de fé, a dissolução dos costumes, a cobiça, a usura, as superstições, entre muitas outras. "Acudí al mundo que está en pasamiento/ no puede vivir ya no gusta nada", diz o poeta (Pregação, 189-190), considerando a proximidade do fim do mundo na visibilidade dos vícios sociais.

Em Sibila Cassandra, a cena da natividade do segundo quadro é a face contrária da exposição dos vícios no primeiro quadro: de um lado, o mundus inversus a exibir o retrato vivo da soberba; de outro, a redenção e a salvação estampadas no retrato vivo da humildade. Para esse fim, a escolha dos personagens centrais do primeiro quadro, Cassandra e Salomão como o casal de orgulhosos que não se acerta, é imprescindível e revela a perspicácia de Gil Vicente para a manipulação de fontes e acervos literários de tradições diversas, seja da herança clássica, seja do universo bíblico.

Salomão, patriarca do Antigo Testamento, entra em cena para espelhar o clássico modelo de noivo do
Cântico dos Cânticos. Poderia ser o sábio vetusto das grandes genealogias hebraicas, mas muitos viram nele certo traço de comicidade, senão de ridículo, na atuação extemporaneamente cortês e no trato amoroso. Spitzer (1959, p. 62-63) nota que a personagem salta abruptamente do cômico para o sábio, e Margarida Mendes (1992, p. 13) admite-lhe um laivo de prosaísmo e divertimento, quando, por exemplo, o patriarca ostenta meia dúzia de posses, incluindo ridículas trinta e duas galinhas, como noivo "bom partido": "Tengo pumares y vinas/ y mil pinas/ de rosas pera holgares/ tengo villas y lugares/ y más treinta y dos galinas" (Cassandra, p. 260-264) 4 . O apaixonado de Cassandra, a sugerir o cantor da tradição bíblica, reveste-se também da linguagem poética de corte, algo afetada (como posteriormente o fará o velho da horta), em oposição ao prosaico ostentador que lhe revela a personalidade: "bien será/ que diga a qué soy venido/y tanto estoy de ti vencido/ que creo que se hará" (Cassandra, p. 30-34).

Mas Salomão não é apenas o afetado amante cortês ou o semostrador de posses: é acima de tudo, e a exemplo de sua amada, um presunçoso, um vaidoso que não poupa uma dúzia de autoelogios, que vão desde a aparência ("Yo soy bien aparentado": Cassandra, p, 51-52) até os bens e haveres (como já mencionados), passando pela presunção de casta e estirpe ("valliente zagal polido": Cassandra, 53), discurso que se aproxima, por exemplo, dos autoelogios que Córidon despeja no seu amado Aléxis, na Bucólica II, de Virgílio, imitada por tão diversos poetas ao longo dos séculos. Trata-se do código do apaixonado tomado pela presunção e pelo próprio orgulho de ser conquistador. Salomão entra em cena movido pela certeza de que a mulher deve curvar-se a suas irrecusáveis investidas matrimoniais, simplesmente porque ele é Salomão. Quando Cassandra recusa-lhe a proposta, ele estampa a face da incredulidade: como ela é capaz de recusar? Poderá haver noivo de mais nobre linhagem? A análise de Leo Spitzer para a peça inclui uma interpretação curiosa para certa fala do patriarca, quando este diz "No me ves?", assim que Cassandra lhe expõe a inacreditável recusa.

\author{
Salamão: No me ves? \\ Casandra: Bien te veo. \\ Salamão: No te creo \\ pues no quieres. \\ Casandra: No te quiero (Cassandra, p. 62-64)
}

\footnotetext{
4 Hart Jr. não acha que a referência às galinhas seja matéria jocosa, porque se insere no imaginário de símbolos cristãos, como as vinhas e as maçãs também ostentadas pelo patriarca. No mais, o número será igualmente simbólico: "We should expect thirty-three, symbolizing the years of Christ's life on Earth. I can only suggest hesitantly that perhaps the number thirty-two refers to the completed years of Christ's life on earth. Allegorically, thirty-two would be highly appropriate, since it is a multiple of four, which symbolizes the world, and eight, the number of resurrection and immortality and hence of Christ" (HART Jr. 1958, p. 44-45).
} 
O diálogo tem tal traço de burlesco que Spitzer o comparou com as ofensivas de Petruchio e Catarina, observando, a exemplo do que já se disse sobre Salomão, a natureza orgulhosa e vaidosa do patriarca: "I see [...] a comical echo of the previous words full of vanity whereby Solomon had recommended himself to Cassandra: [the aunts had wished] Que me veas/y me creas/para hecho de casar, suggesting that to see and to believe him should be enough for Cassandra" (SPITZER, 1959, p. 63).

Portanto, é preciso considerar que, na balança dos opostos, na exposição do jogo de vícios e virtudes, ou antes, na dualidade entre orgulho e humildade, que caracteriza a força doutrinária da peça, não é apenas Cassandra a fazer o polo oposto da Virgem Maria. Também Salomão (mas apenas o Salomão do primeiro quadro, curiosamente ainda não nomeado como tal) move-se diante dos olhos do espectador como figura caracterizadora de um vício, o orgulho, que encontra, no fecho da cena, ou seja, frente à natividade, a sua redenção. Sua trajetória, comum a tantos personagens do primeiro teatro devocional de Gil Vicente, será a mesma de Cassandra: a descoberta de seu erro, a busca pela redenção e pelo arrependimento. Frente ao presépio, o casal se curva e reconhece que tudo são vaidades.

Quanto à presença de Cassandra em cena, adequada para espelhar outra face da soberba, inúmeros leitores vicentistas já decifraram a origem mítica e literária da sibila de tradição grega. As sibilas eram profetizas do mundo antigo que, no dizer de Maria Idalina Rodrigues (1999, p. 195), "passaram da Grécia a Roma, dos romanos aos hebreus, do judaísmo ao cristianismo, por vezes com idênticas advertências a significarem factos diferentes". Cassandra, em especial, presente nos mitos e nas tragédias gregas, recebera de Apolo a inspiração profética, mas, tomado de amores por ela, o deus exigiu que a jovem se entregasse a ele. Ela concordou, mas não cumpriu a promessa. Apolo, furioso, não podendo cassar-lhe a arte divinatória, fez com que tal engenho não fosse acreditado. Isso quer dizer que tudo quanto Cassandra predissesse era verdade, mas ninguém lhe dava crédito (BRANDÃO, 1991, II, p. 189).

Será possivelmente esta a Cassandra que lemos em Gil Vicente? Em parte sim, a considerar que o mestre português a teria conhecido pelo menos da Cronica Troiana (versão galega medieval do ciclo de Tróia), na improbabilidade de ter tido acesso aos códices clássicos. Mas em parte não. É também Maria Idalina Rodrigues (1999, p.206-207) quem nos adverte para fontes mais seguras na leitura do texto vicentino: no romance épico trecentista italiano Il libro del Famosissimo Guerrino detto il Meschino, de Andrea da Barberino (há títulos ligeiramente diferentes para esta obra), vertido para o espanhol em 1512 (o auto de Gil Vicente poderá ser, portanto, de 1513), menciona-se uma sibila Cumana (e não Cassandra), castigada e levada à solidão numa gruta, por ter achado que era a virgem escolhida para ser a mãe de Deus no mundo. A sibila de Barberino, conforme igualmente lemos no auto vicentino, é virgem e soberba. Cumana, ou Cumas, será também a sibila que profetizou a vinda de uma criança de progênie dos mais altos céus, na Bucólica IV de Virgílio, e que foi tida por muitos (Agostinho, Lactâncio) como a profetisa do nascimento de Cristo, crença que se arrastou por toda a Idade Média, tendo possivelmente chegado ao Dante da Divina Comédia, que elege Virgílio como "o poeta dos gentios". Idalina Rodrigues (1999, p. 205) acrescenta ainda que a Cassandra medieval estivera também presente no Libre de Sybille, escrito no séc. XII, por Philippe de Thaon, que a colocou em sexto lugar num rol de dez sibilas (conforme mandava a tradição desde a antiguidade), e com a curiosa "particularidade de anacronicamente a fazer contemporânea de Salomão".

Révah (1959, p. 186), que também estudou a presença do Guerino il Meschino no Auto da sibila Cassandra, e considerando sugestões presentes em outros textos vicentinos, como Exortação da Guerra e Lusitânia, acredita que tais elementos "fournissent également des preuves très convaincantes de l'utilisation du Guarino Mesquino par Gil Vicente". O crítico francês revela ainda a multiplicidade de nomes de sibilas (dez, ao todo) mencionadas pela Cumana de Barberino, a presunçosa que acreditou ser a Virgem Maria, entre elas as "tias" de Cassandra que aparecem no auto vicentino: Eritréia, Pérsica e Ciméria, nomes ligeiramente alterados pelo mestre português em seu auto. Todo esse referencial clássico e, em certa medida, erudito, leva a crer que Gil Vicente não fora tão pouco versado em letras humanistas, como nos tenta convencer Carolina Michaëlis de Vasconcelos (1949), em seu ensaio sobre as leituras supostamente minguadas do dramaturgo português, sempre mantidas à sombra da Bíblia e do breviário da Igreja. Gil Vicente soube, com boa dose de instrução literária, capturar uma gama de personagens altamente significativos para a representação de seu ideário moral.

Juntos, Cassandra e Salomão, portanto, revelam-se faces distintas de uma mesma moeda: o orgulho, a vaidade e a presunção em esferas culturais diferentes, ou seja, no mundo clássico e na tradição judaica. "No quiero dar mi limpeza/ y mi pureza", diz Cassandra às tias (Cassandra, p. 236-237); "Yo soy bien aparentado/ y abastado/ valliente zagal polido", responderá o ofendido Salomão (Cassandra, p. 51-53). É como se ele afirmasse que ela é uma irresponsável por não aceitar tão nobre convite de casamento; e ela replicasse que ele só pode ser insano por achar que pode cortejar tão alta fidalguia, 
porque "yo quiero ser escogida/ en otra vida/ de más perfecta manera" (Cassandra, p. 245-247).

Ainda que todo leitor do Auto da Sibila Cassandra tenha percebido a notória denúncia do orgulho na peça (a própria rubrica inicial da Compilação de 1562 o menciona, antecipando a "presunção da Sebila Cassandra"), é curioso que poucos tenham efetivamente atribuído a esse pecado a sua mais alta dimensão no texto e no contexto histórico da composição vicentina. Spitzer (1959, p.57), por exemplo, mesmo considerando a importância do orgulho na peça, afirma que "the play's central theme is then that of prophecy. All the dramatis personae assume the rôle of 'prophets' and all, except Cassandra, are prophets of Christ's birth from Mary". Mesmo que a leitura do auto nos arraste a possibilidades interpretativas diversas (e filólogos de renome já se debruçaram sobre o texto), não é possível excluir o orgulho, como um dos pecados capitais, na mira dos interesses centrais de Gil Vicente.

Escrevendo no alvorecer do séc. XVI, numa Península Ibérica ainda intoxicada pela gigantesca herança de valores medievais, nosso dramaturgo revela-se, antes de tudo, um pensador ortodoxo, católico devoto que projetou no palco uma variedade de princípios doutrinários políticos e religiosos em que ele possivelmente tenha acreditado. Pensando na atmosfera de fim de mundo, que caracterizou o seu tempo histórico, Gil Vicente ensinou a penitência como reconciliação com Deus e a Igreja, sacramento que se via estampado na clássica representação da natividade. Nesse cenário de abandono das virtudes, ou antes, de um "mundo às avessas" que se rende à adoração do presépio (MENDES, 1992, p. 32), o mestre português será movido por um anseio de levar ao palco os nossos erros, aquela profusão de faltas que a Igreja vinha centrando, desde a Alta Idade Média, num montante de sete pecados capitais (de caput, "cabeça", "origem"), sete que seriam as cabeças, ou a origem, de uma infinidade de outros pecados.

Até o tempo de Gil Vicente, portanto, na Europa, "toda a vida e visão de mundo do homem medieval gira em torno da presença do pecado" (CASAGRANDE e VECCHIO, 2002, II, p. 337), por meio de uma herança que remonta a Evágrio Pôntico, Aurélio Prudêncio, João Cassiano e especialmente a Gregório Magno que, no final do séc. VI, converteu de oito para sete os pecados capitais, hierarquizando-os e classificando-os por ordem decrescente, numa lista que é encabeçada pelo orgulho (pecado maior, desagrado máximo aos olhos de Deus), seguindo-se, então, a inveja, a ira, a preguiça, a avareza, a gula e a luxúria (DRUMMOND, 2014, p. 52). O orgulho, por conseguinte, desde a Alta Idade Média, manteve-se como o mais injurioso dos pecados, vício de todos os vícios, comandante de um exército de outras faltas morais, intensificando-se e, de certa forma, desdobrando-se em seus congêneres: a soberba, a vanglória, a presunção, a vaidade, a arrogância, a jactância, a altivez.

Gil Vicente, que herdou uma boa monta de doutrinação tomista, por certo sabia disto: que a soberba, na Suma Teológica, era a mãe de todos os vícios, raiz da aversão que o homem sente por Deus. O artigo 3 da questão 84 categorizava: "deve-se dizer que a apostasia de Deus é chamada o início da soberba, pela aversão. Pois pelo fato que o homem não quer submeter-se a Deus, segue-se que ele quer de modo não ordenado sua própria excelência nas coisas desde mundo" (AQUINO, 2005, p.452). Casagrande e Vecchio (2002, p. 349) postulam que, pelo menos a partir do séc. XIII, apenas a avareza poderá disputar com o orgulho a primazia de gravidade entre os pecados, e assim mesmo, por causa da condenação da usura e do comércio iniciados pela ascensão da classe mercantil que "assenta no dinheiro suas chances de reconhecimento social". No mais, será o orgulho o chefe supremo de nossas faltas.

O orgulho fora o pecado de Lúcifer, e por extensão, a própria apostasia de Deus por parte do gênero humano. No final do séc. XVI, o bispo e teólogo alemão Peter Binsfeld, ao buscar identificar um nome de demônio para cada pecado do setenário gregoriano, identificou Lúcifer com o orgulho ${ }^{5}$. E John Milton, no século seguinte, fabulou uma epopeia inteira, o Paraíso Perdido, movida por essa personagem extraordinariamente humana, que de Lúcifer volve a Satã, a admitir, do íntimo de seu inferno interior, a soberba como a mola propulsora de sua trágica ação contra Deus ${ }^{6}$. Poucas décadas depois de Gil Vicente, Montaigne exibia sua sutileza de pensamento num ensaio sobre a presunção (que viria depois do ensaio sobre a glória, na sua coletânea), essa "opinião excessivamente boa que concebemos de nosso valor", apta a nos seduzir até mesmo em nome da falsa virtude; afinal, "podemos ser humildes por vaidade" (MONTAIGNE, 2001, II, p. 449 e 451).

Bem antes de Tomás de Aquino pensar a soberba como a mãe de todos os vícios, Agostinho, por um raciocínio bem próximo disso, havia identificado o orgulho com a raiz do próprio pecado original. No tratado sobre $\mathrm{A}$ verdadeira religião, ensina que "o anjo mau, amando-se a si mesmo mais do que a Deus, recusou-se a submeterse, inchou-se de orgulho e, separando-se da essência soberana, arruinou-se" (AGOSTINHO, 2002, p. 50). E nas páginas finais do tratado sobre $\mathrm{O}$ livre arbítrio, uma das

\footnotetext{
As demais classificações são: Asmodeu para a luxúria, Belzebu para a gula, Mammon para a avareza, Belfegor para a preguiça, Azazel para a ira e Leviatã para a inveja.

6 "Is there no place/ Left for repentance, none for pardon left?/ None left but by submission, and that word/ Disdain forbids me" (The annotated Milton, 1999, p. 239): "Por que modo o perdão obter eu posso?/ Só pela submissão... Palavra horrível!/ Meu nobre orgulho atira-te bem longe" (MILTON, 1994, p. 135).
} 
bases teológicas de seu pensamento, o bispo de Hipona expõe um confronto entre o orgulho e a sabedoria, inicialmente pensando o que poderia ter movido a vontade de nossos primeiros pais, e por fim, considerando que "o demônio apresentou-se ao homem como exemplo de orgulho, [enquanto] o Senhor apresentou-se a nós como exemplo de humildade e com a promessa de vida eterna" (AGOSTINHO, 1995, p. 240). A soberba, na teologia agostiniana, vinha igualmente identificada com o amor ao poder da razão (ratio). O confronto entre a superbia (o amor de si e das coisas temporais) e a humilitas (o amor das coisas de Deus), tão apreciado pelos letrados medievais, seria o desfecho de uma obra centrada na condição de liberdade da consciência humana, o livre arbítrio. É o que também pondera Juan Antonio Moreno (2000, p. 289), em estudo sobre a soberba como clausura da consciência, na obra de Agostinho:

Para seguir progresando en el conocer se hace necesario primero darse cuenta de esta limitación de la ratio en su actividad soberbia, y en segundo lugar procurar superar (trascender) dicha limitación. Sólo si llegamos a conocernos a nosotros mismos tal como somos, podremos más adelante dar el salto y conocer con un conocimiento superior a Dios.

Dante, na Divina Comédia, mostrou-se enérgico, como, de resto, sempre fora, na exposição das divergências entre a humildade e o orgulho, legando ao fim da Idade Média uma de suas mais expressivas representações. Aos orgulhosos, dedica pelo menos três cantos do Purgatório (10 a 12), exibindo os pecadores, de maneira vexatória, logo no primeiro terraço (afinal, é o primeiro pecado), numa trincheira cavada na rocha, estreita e tortuosa, onde os penitentes carregam pesadíssimos blocos de pedra. As almas são expostas a representações de modelos de humildade, esculpidos no mármore da encosta, como a lembrar-lhes a cada instante a virtude que se opõe à soberba que os caracterizou em vida. Lá está como a primeira das humildes a Maria da Anunciação, ancilla Dei (Purg. X, 40-45), antítese de Lúcifer, o primeiro dos soberbos (que serão depois representados sugestivamente no chão da encosta), o mais ímpio dos ímpios, anjo nobre que caiu de sua altura pelo orgulho do valor excessivo de si mesmo, aquele "che fu nobil creato/ piú ch'altra creatura" (Purg. XII, 25-26). A ancilla Dei vinha naturalmente do Evangelho de Lucas, o único que centra exclusivamente em Maria o gesto da aceitação e da humildade na cena da Anunciação do anjo, em particular no seu cântico de simplicidade e submissão. Nele, o Senhor dispersou "os que, no coração, alimentavam pensamentos soberbos" (Lc 1:51) e "exaltou os humildes" ( $L c$ 1:52).

Por fim, ainda sobre a dualidade humilitas e superbia, Gil Vicente pode ter conhecido um dos mais importantes livros devocionais que correram a Europa no fim da Idade Média, inclusive a Península Ibérica de seu tempo: a Imitação de Cristo, tratado anônimo do séc. XV sobre a humildade e a renúncia de si, atribuído a Tomás de Kempis, monge alemão que teria copiado de próprio punho a imensa maioria dos capítulos referentes à obra ${ }^{7}$. Os quatro volumes que compunham a obra, para além da exposição da eucaristia como sacramento de reconciliação com Deus, insistiam na humildade como primeira das virtudes cristãs, antítese do orgulho e da presunção, os vícios mais condenados pelos "conselhos úteis para a vida espiritual", conforme ensina o primeiro livro. Lá estão algumas das mais emblemáticas lições para a Cassandra e o Salomão de Gil Vicente, especialmente a condenação da vanglória e do orgulho dos bens e dos talentos próprios, pois orgulhar-se disso é desagradar a Deus, "de quem procede tudo o que a natureza te oferece de bom", pois Ele "eleva os humildes e rebaixa os presunçosos" (A IMITAÇÃO, 1992, p. 33). Em outros termos, o manual ensina que orgulhar-se de seus méritos é não compreender que eles não são efetivamente méritos, mas provêm das dádivas de Deus. Para Cassandra, a obstinada que se recusa a ouvir os conselhos das tias e dos tios profetas, o autor anônimo sentencia: "recursar-se a dar confiança aos outros quando a razão ou o assunto o exigem é sinal de orgulho e teimosia" (idem, p. 35-36).

Todo esse acervo doutrinário medieval sobre o binômio humilitas e superbia estaria mesmo em Gil Vicente? Em tese, sim. Como têm sido infrutíferas as tentativas mais recentes de rastrear a leitura filosófica e literária do mestre português, desde que, conforme já se disse, Carolina Michaëlis de Vasconcelos (1949) recusou-lhe todo saber clássico e humanista, razoável é mesmo compreender o espírito de seu tempo, o Zeitgeist que penetra profundamente as consciências mais sensíveis de uma época. Gil Vicente, católico e ortodoxo, leva ao palco a batalha santa de seu século cortado pelas dissidências religiosas. O belo discurso de Eruteia ("Quando Dios fuere ofendido", vv. 618-652), ao final da peça, é a denúncia do fim de um tempo, em que as virtudes serão negligenciadas, em que Deus será ofendido, a fé, abandonada, e a Igreja, cativada pela cobiça; então "non será mucho alongado,/ mas llegado/ el juicio prometido" (Cassandra, p. 621-623). É o fim de um ciclo, pondera o dramaturgo, o juízo prometido, em que nosso grande inimigo é Lúcifer, o orgulhoso que apaga os últimos vestígios da humildade e da nossa subserviência a Deus. Esse tempo terá chegado, quando se vir "reinar la presunción" (Cassandra, 645). $\mathrm{O}$ discurso de Eruteia insinua-nos a soberba como o pecado de Lúcifer que avançará sobre os homens no

Costa (1989, p. 126) assim se refere ao livro: "essa obra tão lida em Portugal, tanto entre o clero como entre os leigos". 
Juízo Final, qual comandante supremo de uma legião de outros pecados, a trazer consigo a destruição do mundo, a corrupção dos valores, a decadência da Igreja.

A insinuar a batalha entre a soberba e a humildade, como nas prédicas da Imitação de Cristo, o Auto da sibila Cassandra tem um viés fortemente escatológico na sua pintura do "mundo às avessas", conforme este se nos apresenta no primeiro quadro da peça. É o mundo em seu declínio, num tempo em que a humildade é virtude apagada pelo embaraço da presunção, porém um mundo que será exposto ao modelo máximo dessa mesma humildade, na antológica cena do presépio, motivada pela submissão da ancilla Dei, a dizer o seu sim para Deus.

Quando o pioneiro Thomas Hart Jr., em 1958, propôs reconstruir a unidade da composição vicentina por meio dos elementos simbólicos (tarefa que Spitzer retomou e igualmente levou a cabo), o crítico americano registrava a crítica de muitos leitores que viram no vilancete final da peça ("A la guerra/ caballeros esforzados") um elemento contraditório e inconciliável com os demais temas abordados. Afinal, era uma composição sobre as profecias do nascimento de Cristo, sobre o binômio humilitas e superbia, e a milita Christi, ou a guerra dos santos cavaleiros de Cristo, não era matéria que se unisse ao restante da peça. Contrariando leituras de Aubrey Bell e Dámaso Alonso, para quem o vilancete final do auto nada tinha a ver com o restante dos temas, Thomas Hart Jr. (1958, p.51) argumenta que a canção "must be understood as referring to all Christians, for every Christian is, figuratively at least, a miles Christi, a soldier for Christ”. Margarida Vieira Mendes (1992:34), por sua vez, também a respeito da polêmica canção final, esclarece:

De facto, a metáfora militar e guerreia, expressa no refrão $A$ la guerra, adequa-se à milícia cristã da prática das virtudes, reforçada pela Graça divina do Natal. Note-se que, no relato do sonho profético de Ciméria, a Virgem aparecia já com adereços iconográficos de guerreira resplandecente, à maneira do Cântico dos cânticos, e que, no louvor de Salamão, o menino Jesus é capitán.

Mendes reconhece a importância das metáforas militares, inclusive na descrição da virgem profetizada por Ciméria, outra das tias sibilinas de Cassandra, para a composição ideológica do auto. Resta dizer que a guerra mencionada no discurso de Ciméria (vv. 445-483), a par do discurso de Eruteia sobre o Juízo Final e a decadência moral daquele século de ranhuras teológicas, é uma guerra contra o orgulho de Lúcifer, motivo central do auto vicentino, estampado no orgulho dos personagens centrais da peça no primeiro quadro da composição. Sim, a humilde Virgem, ancilla Dei, profetizada por Ciméria vem toda ela armada como guerreira (arnês, elmo, sol), mas especialmente "contra Lucifer armada" (Cassandra, p. 464). Uma vez mais a insinuar a batalha entre a soberba e a humildade, Gil Vicente está pondo em cena, com efeito, uma batalha entre Lúcifer e a Virgem, convidando seus espectadores a uma revisão de valores e mesmo a uma revisão de vida, por meio de uma investigação sobre o pecado do orgulho.

Vieira Mendes (1992, p. 8) observa que, frente ao acervo de argumentações pertinentes, senão sensatas e equilibradas, sobre o casamento na Península Ibérica do fim da Idade Média, a considerar naturalmente a situação desfavorável das mulheres, Cassandra não deveria ser reduzida a "uma alegoria moral do vício da soberba", já que revela igualmente bom senso e inteligência a seu tempo. De fato. Mas Salomão também mostra a contradição do orgulhoso que se torna sábio. O Auto da sibila Cassandra, como muitas outras composições devocionais de Gil Vicente, é uma peça sobre a transformação espiritual dos seres, a partir da revelação do nascimento de Cristo. O Salomão do primeiro quadro, presunçoso e vaidoso de seu papel cortesão, não é o mesmo Salomão do segundo quadro, pio e devoto na frente do presépio. O mesmo se dá com Cassandra. Não importa ao dramaturgo as diversidades que denunciam, a nossos olhos modernos, as supostas contradições dos personagens, flagrados em seus "duplos papéis" (soberbos, num instante, humildes e devotos, no outro). Não se trata (como, de resto, acontece em todo o teatro vicentino) de personagens com uma psicologia própria: cada um deles entra em cena, em quadros diferentes do auto, como que a representar uma circunstância distinta da condição humana, seja a estultícia e o orgulho, seja a sabedoria e a humildade, como entende uma análise arguta de Spitzer (1959, p. 63): "Gil Vicente obviously composed his play not according to the requirement of psychological consistency, but [...] according to the logic of the diferent particular scenes".

Dessa forma, Cassandra e Salomão devem ser lembrados, sim, como os orgulhos que se voltaram à humildade, modelos da condição humana que se armaram contra a soberba de Lúcifer, frente às revelações dos mistérios do nascimento de Cristo. Muitos outros personagens de Gil Vicente, em especial nessa primeira fase de seu teatro devocional, fizeram o mesmo. Inseridos no ciclo da natividade dos mistérios e das moralidades da dramaturgia medieval, são indivíduos tocados pela revelação: de soberbos, veem-se humildes, armados, qual guerreiros da militia Christi, contra as astúcias de Lúcifer. Era o mestre português num de seus melhores momentos da primeira fase, a confirmar e fortalecer a tese agostiniana sobre as divergências entre superbia e humilitas, expondo à sua plateia o modelo máximo da humildade, a ancilla Dei do Evangelho de Lucas. Frente à decadência dos valores, e 
às voltas com o terrível vaticínio do Juízo Final, Salomão e Cassandra provam, no entanto, que ainda é possível mover-se para a direção das virtudes.

\section{Referências}

AGOSTINHO, Santo. A verdadeira religião. O cuidado devido aos mortos. Trad. Ir. Nair de Assis Oliveira. São Paulo: Paulus, 2002.

AgOSTINHO, Santo. O livre arbitrio. 3. ed. Trad. Ir. Nair de Assis Oliveira. São Paulo: Paulus, 1995.

A IMITAÇÃO DE CRISTO. Trad. Luiz João Gaio. São Paulo: Loyola, 1992.

ALÇADA, João Nuno. Por ser cousa nova em Portugal. Oito ensaios vicentinos. Coimbra: Angelus Novus, 2003.

ALIGHIERI, Dante. La Divina Commedia. Milano: Ulrico Hoepli, 1955.

AQUINO, Tomás de. Suma Teológica. 2. ed. São Paulo: Loyola, 2005. v. IV.

AS OBRAS DE GIL VICENTE. Dir. José Camões. Lisboa: Imprensa Nacional - Casa da Moeda, 2002. 5 v.

BERNARDES, José Augusto Cardoso. Gil Vicente. Lisboa: Edições 70, 2008.

BÍBLIA SAGRADA. Trad. João Ferreira de Almeida. Barueri: Sociedade Bíblica do Brasil, 2008.

BRANDÃO, Junito. Dicionário mítico-etimológico da mitologia grega. Petrópolis: Vozes, 1991. 2 v.

CASAGRANDE, Carla; VECCHIO, Silvana. Pecado. In: LE GOFF, Jacques; SCHMITT, Jean-Claude. Dicionário temático do Ocidente Medieval. Bauru/São Paulo: Edusc/Imprensa do Estado de São Paulo, 2002.

COSTA, Dalila Pereira da. Gil Vicente e sua época. Lisboa: Guimarães Editores, 1989.

DRUMMOND, Albert. As constituintes da moral medieval católica: como os vícios humanos se tornaram os sete pecados capitais. Revista Mundo Antigo, v. 3, n. 5, p. 41-62, 2014.

FREIRE, Anselmo Braacamp. Vida e obras de Gil Vicente: trovador, mestre da balança. 2. ed. Lisboa: Revista "Ocidente", 1944.
HART Jr., Thomas R. Gil Vicente's Auto de la Sibila Casandra. In: Hispanic Review, v. 26, n. 1, p. 167-193, 1958.

KEATES, Laurence. $O$ teatro de Gil Vicente na corte. Lisboa: Teorema, 1988.

MENDES, Margarida Vieira. Cassandra. Lisboa: Quimera, 1992. (Coleção "Vicente").

MILTON, John. O Paraíso Perdido. Trad. António José Lima Leitão. Belo Horizonte: Villa Rica, 1994.

MONTAIGNE, Michel de. Ensaios. Trad. Rosemary Costhek Abílio. São Paulo: Martins Fontes, 2001. v. II.

MORENO, Juan Antonio. La soberbia y la clausura en el pensamiento de S. Agustín. In: Thémata, n. 25, p. 285-292, 2000.

RÉVAH, I. S. L'Auto de la Sibylle Cassandre de Gil Vicente. In: Hispanic Review, v. 27, n. 2, p. 167-193, 1959.

RODRIGUES, Maria Idalina R. Deambulações e inquietações em torno do Auto da Sibila Cassandra. In: Via Spiritus, n. 6, p. 193-225, 1999.

SARAIVA, Antonio José. Gil Vicente e o fim do teatro medieval. 3. ed. Lisboa: Publicações Europa-América, 1970.

SARAIVA, Antonio José. História da cultura em Portugal. Lisboa: Gradiva, 2000. Vol. 2: Gil Vicente, reflexo da crise.

SPITZER, Leo. The Artistic Unity of Gil Vicente's Auto da Sibila Casandra. In: Hispanic Review, v. 27, n. 1, p. 56-77, 1959.

TEYSSIER, Paul. Gil Vicente: o autor e a obra. Amadora: Ministério da Educação e das Universidades, 1982.

THE ANNOTATED MILTON: Complete English Poems. Ed. Burton Raffel. New York: Bantam Books, 1999.

VASCONCELOS, Carolina Michaëlis de. Notas vicentinas: preliminares duma edição crítica das obras de Gil Vicente. Lisboa: Revista "Ocidente", 1949.

VICENTE, Gil. Auto da sibila Cassandra. Org. de Alexandre Soares Carneiro e Orna Messer Levin. São Paulo: Cosac Naify, 2007. 